\title{
Aprendizaje colaborativo y uso de las redes sociales en educación primaria
}

\author{
Teresa FERNÁNDEZ ULLOA \\ California State University, Bakersfield \\ Department of Modern Languages and Literatures \\ tfernandez_ulloa@csub.edu/fernandezt@hotmail.es
}

Recibido: abril 2012

Aceptado: diciembre 2012

\section{RESUMEN}

En este artículo se mostrará la importancia que tienen en el proceso de enseñanzaaprendizaje las Tecnologías de la Información y Comunicación, el aprendizaje colaborativo y las redes sociales (Facebook y Twitter). Se explicarán algunas actividades en relación con las redes sociales que pueden realizarse en educación primaria.

Palabras clave: redes sociales, aprendizaje colaborativo, Facebook, Twitter

Apprentissage collaboratif et usage des réseaux sociaux dans la éducation primaire

\section{RÉSUMÉ}

Dans cet article nous montrons l'importance des nouvelles technologies de l'information et de la communication, l'apprentissage collaboratif et les réseaux sociaux (Facebook et Twitter). Nous expliquerons quelques activités liées a l'emploi des réseaux sociaux dans la éducation primaire.

Mots-clé: réseaux sociaux, apprentissage collaborative, Facebook, Twitter

\section{Collaborative learning and usage of social networks}

\begin{abstract}
In this article, we point out the importance of Technologies of Information and Communication, collaborative learning, and social networks (Facebook and Twitter) in education. We will show several activities for primary education in which we use social networks.
\end{abstract}

Keywords: social networks, collaborative learning, Facebook, Twitter

\section{SUMARIO}

1. Introducción. 2. Aprendizaje colaborativo. 3. Redes sociales. 4. Facebook y twitter. 4.1. Twitter. 4.2. Facebook. 4.2.1. ¿Cuáles son sus ventajas más significativas? 4.2.2. ¿de qué servicios de facebook se puede beneficiar un docente para enseñar? 4.3. Objetivos. 4.4. Usos y actividades. 5. Conclusiones. Bibliografía 


\section{INTRODUCCIÓN}

En los años 60 se empezó a utilizar la Web 1.0, Internet de primera generación, que es un estado estático, es decir, los datos que se encuentran en ella no pueden cambiar, se encuentran fijos, no se actualizan. Una web personal o el correo electrónico serían del tipo 1.0.

En el año 2004 se empezó a hablar de la web $2.0^{1}$, también denominada web social (es la que utilizamos en la actualidad). La Web 2.0 representa la evolución de las aplicaciones tradicionales hacia aplicaciones web enfocadas al usuario final. Es una actitud, más que una tecnología. Se trata de aplicaciones que generan colaboración, y servicios que reemplazan las aplicaciones de escritorio. Un blog, facebook $\mathrm{y}$ twitter son servicios del tipo 2.0.

La Web 2.0 está asociada estrechamente a Tim O'Reilly, debido a la conferencia sobre la Web 2.0 de O'Reilly Media en el año 2004. Aunque el término sugiere una nueva versión de la World Wide Web, no se refiere a una actualización técnica de 1.0, sino a la forma en que se usa, pues es cualitativamente diferente. Para compartir, se usan en ella una serie de herramientas entre las que destacan los blogs (espacio web personal en el que el autor escribe cronológicamente artículos o noticias, incluye fotos, enlaces..., pero que es además un espacio colaborativo donde los lectores pueden incluir también sus comentarios, llamados entradas o posts). También hay wikis (espacio web corporativo organizado mediante una estructura hipertextual de páginas donde varias personas autorizadas elaboran contenidos de manera asíncrona; hay varios de tipo gratuito, como Mediawiki o Twiki), plataformas educativas (Moodle, WebCt, Blackboard) y redes sociales (Facebook, Twitter) ${ }^{2}$.

Es decir, esta Web, en comparación con la anterior, permite a los usuarios interactuar tanto con el contenido de las páginas (comentarios, respuestas, citas...), como con otros usuarios a través de diferentes herramientas.

L. García Aretio (2007: 3) señala que "en la 1.0 participábamos más sólo como consumidores y en la 2.0, haciéndolo también como consumidores, nos convertimos a la par en productores y creadores. $\mathrm{Y}$ esa producción $\mathrm{y}$ creación la hacemos con plena libertad".

Las características de una herramienta 2.0 serían:

- El sitio no debe actuar como un "jardín cerrado"; la información debe poderse introducir y extraer fácilmente.

- Los usuarios deberían controlar su propia información.

- Está basada exclusivamente en la Web: los sitios Web 2.0 con más éxito pueden ser utilizados enteramente desde un navegador.

- La existencia de enlaces o links es requisito imprescindible.

\footnotetext{
${ }^{1}$ Véase http://www.maestrosdelweb.com/editorial/web2/

${ }^{2}$ Véase R. Palomo López, J. Ruiz Palmero y J. Sánchez Rodríguez (2008).
} 
En este mundo virtual los cambios se producen a gran velocidad, y su influencia, como demuestra el uso de los blogs, el fenómeno de intercambio de vídeos o mundos virtuales como Second Life (en los que ya se dan clases), es grande.

En los próximos años, con la implantación de la Web $3.0^{3}$, el gran objetivo será transformar la red en una base de datos, hacer los contenidos accesibles por aplicaciones non-browser, dotar a las páginas Web de una mayor significación (web semántica), fomentar las tecnologías de inteligencia artificial, la Web 3D... Esta Web estará adaptada a las circunstancias de cada usuario, a sus intereses y peculiaridades, dándoles mayor significado a las preguntas que se les planteen.

Las Nuevas Tecnologías de la Información y Comunicación, por tanto, han hecho cambiar la manera de pensar y de ver el mundo. Así lo refleja R. MartínLaborda (2005: 4) al indicar que "los efectos que Internet y sus múltiples aplicaciones tienen en la vida de los ciudadanos, de las empresas, de las instituciones y de los gobiernos se han manifestado en menos de una década. Si miramos a nuestro alrededor, se observan muchos cambios en la forma de comunicarse, de organizarse, incluso de trabajar o de divertirse".

J. López Sánchez (2007: 1) también apunta que "la globalización impuesta por las TIC en la Información y en la Comunicación supone un cambio en las formas de generar el conocimiento. Ahora el conocimiento se genera y comparte en comunidad".

Los docentes tendrán que adaptarse a esos cambios para que la escuela no quede anticuada y no siga sucediendo lo que dice J. A. Aunión (2009): "el problema es que los profesores del siglo XX intentan educar a jóvenes del siglo XXI en unas escuelas del siglo XIX".

$Y$ ello es así, ya que, a pesar de tener a nuestro alcance gran cantidad de recursos educativos, existe una resistencia al cambio en cuanto a los modelos educativos y a la formación continua de los profesionales que están inmersos en este ámbito. Los docentes que aún piensan de esta forma no son conscientes de que están enseñando a un tipo de alumnado muy diferente al de décadas anteriores, ya que ahora las TIC forman parte de sus vidas.

Así lo explica J. M. Sancho (2008: 21) al afirmar que "las generaciones nacidas desde 1980 han crecido en un contexto en el que las tecnologías digitales son parte consustancial de su vida cotidiana, ya que la mayor parte de sus actividades en

${ }^{3}$ Véase http://es.wikipedia.org/wiki/Web_3.0 
relación con la comunicación entre iguales y la gestión del conocimiento están, en un sentido amplio, mediadas por las tecnologías".

Todo ello da lugar a que se esté empezando a hablar de las "tecnologías del aprendizaje y del conocimiento" (TAC). Para J. M. Sancho (2008: 20) "pasar de TIC a TAC implica mucho más que el cambio de una simple vocal, ya que son un instrumento de inclusión digital en el ámbito educativo. Es decir, éstas no solamente cumplen la función de integrar las TIC en el aula, sino de intentar que las TIC sean un recurso para el aprendizaje y un agente de innovación educativa".

En el siglo XX, los centros educativos daban mucha importancia al aprendizaje de la tecnología, sin embargo, actualmente, y debido a que los avances tecnológicos ya son parte de nuestra vida, la situación ha cambiado, dando prioridad no tanto a "aprender de" la tecnología, sino a "aprender a través de" ella. La tecnología debe ser una facilitadora del aprendizaje personal; se trata más de desarrollar competencias que conocimientos.

En España, en la Ley Orgánica de Educación (LOE), 2/2006 de 3 de mayo, publicada en el BOE (boletín oficial del Estado), 106, 4 de mayo de 2006, se hace referencia a una aproximación de las tecnologías de la Información y comunicación: "Sin perjuicio de su tratamiento específico en algunas de las áreas de la etapa, la comprensión lectora, la expresión oral y escrita, la comunicación audiovisual, las tecnologías de la información y la comunicación y la educación en valores se trabajarán en todas las áreas" (apartado 2, artículo 19, capítulo II, título I).

De igual manera, y según el Real Decreto 1513/2006, de 7 de diciembre, por el que se establecen las enseñanzas mínimas de la Educación Primaria, hay que "iniciarse en la utilización, para el aprendizaje, de las tecnologías de la información y la comunicación desarrollando un espíritu crítico ante los mensajes que reciben y elaboran" (apartado i, artículo 3).

\section{APRENDIZAJE COLABORATIVO}

Las ideas que aportaremos en este artículo sobre cómo usar las redes sociales van dirigidas a la etapa de Educación Primaria. Según lo establecido en la LOE, esta etapa comprende "seis cursos académicos que se cursarán ordinariamente entre los seis y los doce años de edad" (apartado 1, artículo 16, capítulo II, título I). "La acción educativa en esta etapa procurará la integración de las distintas experiencias y aprendizajes del alumnado y se adaptará a sus ritmos de trabajo" (apartado 3, artículo 16, capítulo II, título I).

Una vez mencionados estos dos principios básicos que establece la LOE, es importante destacar que este trabajo va a estar centrado en el área de Lengua Castellana y Literatura a la hora de plantear actividades. Por tanto, se tendrá en cuenta que trabajen al menos algún aspecto de los que indica la LOE: "la 
comprensión lectora, la expresión oral y escrita, la comunicación audiovisual, las tecnologías de la información y la comunicación y la educación en valores" (apartado 2, artículo 19, capítulo II, título I).

De todos los objetivos que plantea la LOE para la Educación Primaria, hay dos que tienen que ver con esta materia (apartados e, i, artículo 17, capítulo II, título I):

Conocer y utilizar de manera apropiada la lengua castellana y, si la hubiere, la lengua cooficial de la Comunidad Autónoma y desarrollar hábitos de lectura. Iniciarse en la utilización, para el aprendizaje, de las tecnologías de la información y la comunicación desarrollando un espíritu crítico ante los mensajes que reciben y elaboran.

Intentaremos mostrar actividades en las que los alumnos, a través de un aprendizaje colaborativo, utilizan las redes sociales como herramienta educativa. Este tipo de aprendizaje es muy importante en el presente, tal y como queda reflejado en el Real Decreto 1513/2006, de 7 de diciembre, más concretamente, en el anexo I, apartado 4, que trata sobre el Tratamiento de la Información y Competencia Digital:

ser competente en la utilización de las tecnologías de la información y la comunicación como instrumento de trabajo intelectual incluye utilizarlas en su doble función de transmisoras y generadoras de información y conocimiento. Igualmente permite aprovechar la información que proporcionan y analizarla de forma crítica mediante el trabajo personal autónomo y el trabajo colaborativo, tanto en su vertiente sincrónica como diacrónica, conociendo y relacionándose con entornos físicos y sociales cada vez más amplios

Es un aprendizaje que se sustenta en el cognitivismo, rechazándose la observación pasiva, la repetición y la memorización.

Son muchos los autores que se proponen encontrar diferencias entre este aprendizaje y otros basados en aprendizajes en equipo, como, por ejemplo, el aprendizaje cooperativo.

Según C. Coll y C. Monereo (2008: 235):

el aprendizaje cooperativo supone esencialmente un proceso de división del trabajo: los participantes acuerdan ayudarse unos a otros en actividades dirigidas a lograr las metas individuales de cada persona. En cambio, en la colaboración, cada miembro del grupo contribuye a la resolución conjunta del problema; la colaboración depende, por ello, del establecimiento de un lenguaje y significados comunes respecto a la tarea, y de una meta común al conjunto de participantes.

M. L. Carrió (2006: 9) apunta que "en el aprendizaje colaborativo cada participante asume su papel dentro del grupo, como líder de los conocimientos que 
se le han asignado, pero cada uno comprende que el equipo necesita de él para completar los conceptos que el grupo desea conocer". En esta situación, cada participante dará lo mejor de sí mismo a la hora de aportar su conocimiento al equipo, considerándose como líder de su propio trabajo, ya que en este aprendizaje no existe un único líder.

Según indica un documento de la Vicerrectoría Académica del Instituto Tecnológico y de Estudios Superiores de Monterrey:

En su sentido básico, aprendizaje colaborativo (AC) se refiere a la actividad de pequeños grupos desarrollada en el aula. Aunque el aprendizaje colaborativo es más que el simple trabajo en equipo por parte de los estudiantes, la idea que lo sustenta es sencilla: los alumnos forman "pequeños equipos" después de haber recibido instrucciones del profesor. Dentro de cada equipo los estudiantes intercambian información y trabajan en una tarea hasta que todos sus miembros la han entendido y terminado, aprendiendo a través de la colaboración.

Es una nueva manera de trabajar en el aula, que supone una forma diferente de concebir la enseñanza, dando paso a la participación, la colaboración y la interacción entre los alumnos y el docente, dejando de lado el trabajo y la actitud individualistas, que hacen prevalecer los conflictos, frustraciones y complejos de los miembros del grupo, impidiendo una plena interacción y un resultado positivo.

Hay unos elementos que siempre están en este tipo de aprendizaje: cooperación, responsabilidad, comunicación, trabajo en equipo y autoevaluación.

Lo que supone la cooperación entre alumnos es que

los estudiantes se apoyan mutuamente para cumplir con un doble objetivo: lograr ser expertos en el conocimiento del contenido, además de desarrollar habilidades de trabajo en equipo. Los estudiantes comparten metas, recursos, logros y entendimiento del rol de cada uno. Un estudiante no puede tener éxito a menos que todos en el equipo tengan éxito. (Vicerrectoría Académica del Instituto Tecnológico y de Estudios Superiores de Monterrey, p. 3)

Por otro lado, es necesario que, en los equipos que se formen, los alumnos tomen una actitud de responsabilidad, tanto en su trabajo como en el de sus compañeros, ya que es necesario que todos los integrantes del grupo se preocupen no sólo de su trabajo sino también del de los demás. Así pues, es importante que los alumnos se comuniquen entre ellos, que intercambien información y que se ayuden de manera efectiva, resolviendo los problemas que se les puedan plantear en un momento dado y aportando soluciones grupales a esas dificultades.

Este aprendizaje basado en la elaboración de equipos para trabajar en el ámbito educativo es muy enriquecedor para los alumnos de Educación Primaria, ya que a la mayoría les suele dar la misma vergüenza que a los adultos el hablar en público. Las personas se suelen desenvolver mejor hablando en grupos reducidos que ante 
un gran público, por eso, los docentes que dan la oportunidad a sus alumnos de trabajar en equipos colaborativos, conseguirán que éstos se sientan más a gusto a la hora de opinar, innovar, etc. Así lo refleja la Vicerrectoría Académica, Instituto Tecnológico y de Estudios Superiores de Monterrey:

Los grupos pequeños representan oportunidades para intercambiar ideas con varias personas al mismo tiempo, en un ambiente libre de competencia, mientras que las discusiones de todo un grupo tienden a inhibir la participación de los estudiantes tímidos. Un grupo formal y cuidadosamente construido ayuda a los estudiantes a aprender a trabajar duro y en equipo en un ambiente seguro y estimulante.

Al trabajar a través del aprendizaje colaborativo hay que tener en cuenta los diferentes métodos que existen para organizar los equipos. Este tipo de aprendizaje requiere que los docentes utilicen métodos creativos. En el artículo que acabamos de mencionar, se destacan varios de estos métodos: "método matemático, método centrado en estados, capitales o áreas geográficas..." (p. 5). Por ejemplo, el profesor que emplee éste último método podrá hacer grupos en su aula elaborando una lista de los países preferidos por sus alumnos o, por el contrario, de los menos valorados para ir de viaje.

En este tipo de aprendizaje también se les permite a los alumnos autoevaluarse, es decir, ser objetivos consigo mismos y hablar sobre las dificultades que hayan podido tener a la hora de desarrollar la tarea planteada por el profesor. Esta autoevaluación les servirá para ver los aspectos mejorables del trabajo y, así, no volver a cometer los mismos errores.

Otro aspecto importante a tener en cuenta cuando hacemos referencia al aprendizaje colaborativo es el cambio de roles que se produce entre estudiantes y profesores (C. A. Collazos, L. Guerrero y A. Vergara, 2001: 3). A los alumnos se les considera como agentes activos de su proceso de enseñanza y aprendizaje, y a los docentes, como guías que facilitan y regulan ese proceso.

Más concretamente, los autores mencionados apuntaban la idea de que ''los estudiantes que verdaderamente se comprometen en este tipo de aprendizaje son personas responsables en su aprendizaje, que están motivadas, que les gusta colaborar y que son estratégicos"' (p. 20).

De todas estas características, cabe destacar la motivación y capacidad de ser estratégico.

G. Bernaza y F. Lee (2005: 7) consideran que "el trabajo colaborativo favorece la motivación intrínseca, basada en la satisfacción y el gozo de incrementar los conocimientos y la competencia propios, de beneficiar a los otros, etc. La motivación puede reflejarse en: éxito, curiosidad epistémica, compromiso con el aprendizaje, persistencia en la tarea, expectativas de éxito futuro y nivel de aspiración”. 
En cuanto a la capacidad para ser estratégico, C. A. Collazos, L. Guerrero y A. Vergara se refieren al hecho de que:

Los estudiantes continuamente desarrollan y refinan el aprendizaje y las estrategias para resolver problemas. Esta capacidad para aprender a aprender (metacognición) incluye construir modelos mentales efectivos de conocimiento y de recursos, aun cuando los modelos puedan estar basados en información compleja y cambiante. Este tipo de estudiantes son capaces de aplicar y transformar el conocimiento con el fin de resolver los problemas de forma creativa y son capaces de hacer conexiones en diferentes niveles.

En cuanto al rol del docente, un profesor que está inmerso en un proceso de aprendizaje colaborativo con un grupo numeroso de alumnos, tiene muchas responsabilidades que desempeñar. La Vicerrectoría Académica, Instituto Tecnológico y de Estudios Superiores de Monterrey (p. 9), señala algunas de ellas: "motivar al alumnado despertando su interés antes de introducir un nuevo concepto o tema, proporcionar experiencias concretas antes de explicar ideas abstractas, asegurarse de que lo explicado se haya entendido, dar a los alumnos oportunidades de reflexión ante informaciones nuevas, revisar el material antes de un examen, etc."

También tenemos que ser conscientes de que los roles del equipo docente de un centro educativo han cambiado con esta metodología. F. Negre y A. Pérez Garcías (2010) lo ven como un "colectivo que apoya, discute, propone y desarrolla nuevos proyectos de innovación buscando la colaboración de la comunidad y la familia y dando respuesta a los retos educativos, sociales y culturales del momento actual".

Hasta aquí hemos visto que el aprendizaje colaborativo, por tanto, tiene un componente importante que tiene que ver con lo social, ya que se trata de aprender junto a otras personas y compartir conocimientos para llegar a un objetivo común. En la actualidad, este aprendizaje se puede desarrollar de distintas maneras: el uso de ordenadores, de las TIC y de las redes sociales son algunas de ellas. Al hecho de utilizar el ordenador en este tipo de aprendizajes se le denomina "Aprendizaje Colaborativo Asistido por Ordenador' (ACAO).

Según M. L. Carrió (2006: 29) este aprendizaje es "una estrategia de enseñanzaaprendizaje por la cual interactúan dos o más sujetos para construir el aprendizaje, a través de discusión, reflexión y toma de decisión, proceso en el cual los recursos informáticos actúan como mediadores". Según esto, podemos considerar que el aprendizaje colaborativo se beneficia de las nuevas tecnologías $\mathrm{y}$, por tanto, se relaciona con las redes sociales.

Entre los beneficios de las TIC en las clases y en el grupo de colaboración, M. L. Carrió (2006: 29) destaca:

- Facilitar el aprendizaje colaborativo, ya que se puede compartir información, mediante ficheros, contactar rápidamente, realizar foros de discusión... 
- Se puede realizar un seguimiento del progreso de los integrantes del grupo a través de las acciones que realizan y que automáticamente podemos seguir con las nuevas tecnologías. Esto era imposible anteriormente ya que la transmisión de la información era muy lenta.

- Difundir las experiencias y poder contactar con otros grupos que realicen experiencias similares, compartiendo conocimientos y fuentes bibliográficas.

- Investigar sobre distintos logros con otros grupos aunque estén en lugares muy distintos.

\section{REDES SOCIALES}

En relación con lo anterior, es importante hacer mención a otro concepto que forma parte del campo de la educación y que tiene mucho que ver con el aprendizaje colaborativo: el "E-learning", también conocido como "aprendizaje en red", "aprendizaje virtual", "educación electrónica", etc.

Se trata de un modelo formativo distinto del que viene siendo habitual y que se apoya en la utilización de diferentes herramientas en la red como recurso indispensable del proceso de enseñanza y aprendizaje del alumnado.

Las redes sociales son estructuras sociales que permiten a las personas establecer un contacto para intercambiar información. Los usuarios que acceden a ellas lo hacen para estar en conexión con diferentes personas, tales como amigos, familiares, compañeros de trabajo, de la universidad, etc.

Actualmente existen profesores que tienen miedo a utilizar las redes sociales con fines educativos en sus aulas debido a diferentes razones. Según apuntan C. A. Collazos, L. Guerrero y A. Vergara (2001: 4), los profesores temen que al utilizar las redes sociales les suceda algo de lo siguiente:

- Pérdida de control en la clase.

- Falta de preparación por parte de los profesores.

- Miedo a no cubrir el contenido.

- Falta de materiales preparados para usar en la clase.

Sin embargo, todo docente que haya utilizado alguna vez las redes sociales en sus aulas habrá podido comprobar que tienen muchas ventajas. M. J. García Granja (2010: 2) cita algunas de ellas:

- Motivación en el proceso educativo, ante la confianza por parte del profesor de cierta autonomía y libertad de acción y la conexión de esta forma de trabajo con sus propias aficiones personales.

- Estimulación del aprendizaje autónomo, en interacción con los demás.

- Facilidad e incentivación de la comunicación y del conocimiento mutuo de los participantes. Lo que también redunda en una ayuda a la labor docente, el poder conocer el profesor el perfil de su alumnado para la elaboración de la materia y al poder mantener un contacto virtual más ágil y continuo.

- Favorece la retención de lo aprendido ya que aprenden haciendo. 
- Práctica de la capacidad de expresión escrita y en el manejo de las TIC.

- Gratuidad del servicio gratuito, ya que no depende del software local.

- Prolongación del proceso de aprendizaje más allá del espacio físico y temporal del centro.

- Incentivación del aprendizaje activo, en el que el alumnado se convierte en el agente de su propio aprendizaje y el profesor abandona el liderazgo como única fuente de conocimiento.

- Revalorización del trabajo en equipo.

- Posibilidad de integración de contenidos propios y de otros profesores de distintas procedencias y ubicaciones geográficas.

- Estimulación de los progresos y logros mediante la opción de mandar 'regalos virtuales' al alumnado, como medio de incentivación del proceso de aprendizaje.

- Permite la creación de grupos especializados en algún tema específico dentro de la propia red, por lo que es posible realizar una sola red y aplicarla para varias asignaturas o varios grupos de alumnos.

- Se puede incorporar artículos y noticias externos usando la tecnología rss ${ }^{4}$.

El mismo autor señala que también hay peligros, el principal, la pérdida de control sobre las entradas a foros y blogs de debate y la intrusión de personas que no pertenecen al aula (p. 3). La solución es regularlo desde el apartado de configuración de privacidad, donde el tutor figurará como moderador. No hay que olvidar que la mayoría de los jóvenes que emplean las redes sociales lo hacen únicamente como medio de ocio, por ello es necesario que los docentes formemos a nuestros alumnos cuando vayamos a trabajar con ellas, explicándoles que hay que tener cuidado con lo que se sube, pues nunca se sabe quién lo va a ver, y que no hay que creerse todo lo que se ve o lee en la red. Estamos dándoles, de esta manera, una alfabetización digital, necesaria en nuestra sociedad actual.

\section{FACEBOOK Y TWITTER}

De entre todas las redes sociales que tenemos a nuestra disposición actualmente, Facebook y Twitter van a ser el centro de esta propuesta didáctica. Ambas son herramientas gratuitas y cuentan con millones de usuarios, ya que permiten fácilmente la comunicación.

4 "RSS son las siglas de Really Simple Syndication, un formato XML para sindicar o compartir contenido en la web. Se utiliza para difundir información actualizada frecuentemente a usuarios que se han suscrito a la fuente de contenidos. El formato permite distribuir contenidos sin necesidad de un navegador, utilizando un software diseñado para leer estos contenidos RSS (agregador). A pesar de eso, es posible utilizar el mismo navegador para ver los contenidos RSS. Las últimas versiones de los principales navegadores permiten leer los RSS sin necesidad de software adicional.” http://es.wikipedia.org/wiki/RSS 
Una vez que hemos explicado brevemente lo que son las redes sociales, cómo están consideradas en el ámbito educativo, sus ventajas pedagógicas, etc., vamos ahora a detenernos en qué y cómo son Facebook y Twitter, pero no sin antes hacer referencia a un aspecto importante que tenemos que tener en cuenta los docentes a la hora de generar una red social con fines educativos: para que los alumnos puedan crear una cuenta personal es necesario que tengan, al menos, 14 años.

En la legislación española, el tratamiento de datos de los menores de edad viene reflejado en el Real Decreto 1720/2007, de 21 de Diciembre, en el que se aprueba el Reglamento de desarrollo de la Ley Orgánica 15/1999, de 13 de diciembre, de protección de datos de carácter personal. Más concretamente, el artículo 13 dice lo siguiente: "Podrá procederse al tratamiento de los datos de los mayores de catorce años con su consentimiento, salvo en aquellos casos en los que la Ley exija para su prestación la asistencia de los titulares de la patria potestad o tutela. En el caso de los menores de catorce años se requerirá el consentimiento de los padres o tutores".

Según esto, todos los docentes de la etapa de Educación Primaria que quieran hacer uso de las redes sociales en el contexto educativo, deberían programar una reunión con todas las familias de sus alumnos, para que estos estén totalmente informados sobre cómo se va a trabajar en torno a las redes sociales y para que decidan si autorizan a sus hijos o no.

\subsection{Twitter}

Twitter es una red social gratuita y de muy fácil manejo que surgió en el año 2006 (aunque su gran auge se produjo en el 2007), creada por un grupo de jóvenes estadounidenses con una idea clara: transmitir a un grupo de personas lo que hacían en cada momento a través de mensajes escritos.

Así fue la primera idea de esta red social y así es como la conocemos actualmente, como una red de mensajería instantánea, basada en un servicio de microblogging $^{5}$ a través del cual las personas podemos tanto enviar (o publicar) como recibir mensajes.

A los mensajes que se les denomina en el "mundo Twitter" Tweets y tienen una característica bastante significativa, ya que solamente se permite escribir un máxi-

\footnotetext{
5 "El microblogging, también conocido como nanoblogging, es un servicio que permite a sus usuarios enviar y publicar mensajes breves (alrededor de 140 caracteres), generalmente sólo de texto. Las opciones para el envío de los mensajes varían desde sitios web, a través de SMS, mensajería instantánea o aplicaciones ad hoc.

Estas actualizaciones se muestran en la página de perfil del usuario, y son también enviadas de forma inmediata a otros usuarios que han elegido la opción de recibirlas. El usuario origen puede restringir el envío de estos mensajes sólo a miembros de su círculo de amigos, o permitir su acceso a todos los usuarios, que es la opción por defecto." http://es.wikipedia.org/wiki/Microblogging
} 
mo de 140 caracteres por cada mensaje; así pues, las personas que quieren expresar algo, lo deberán hacer de manera breve y concisa.

Los que accedemos a esta red lo hacemos principalmente por dos razones: la primera, para escribir mensajes en el tablón expresando alguna opinión, estado, etc., o bien para ver los posibles mensajes que dejan publicados el grupo de personas a los que sigues. Seguir a alguien significa que estás suscrito a sus Tweets como un seguidor (followers), que sus actualizaciones aparecerán en tu cronología y que esa persona tiene permiso para enviarte Tweets privados, llamados mensajes directos (DM). Puedes proteger tus Tweets y de esta forma los que quieran seguirte debe mandar una petición, pues en principio te puede seguir cualquiera, aunque Twitter te envía un correo cuando alguien nuevo te sigue. Solo los seguidores que apruebes pueden ver tus Tweets. Seguir en Twitter no es como añadir un amigo en otras redes sociales puesto que no es mutuo. Si alguien quiere seguirte, tú no tienes por qué seguirlo a él.

Otros conceptos que conviene manejar:

@username (nombre de usuario). Este término lo utilizamos cuando escribimos un tweet a una persona en particular.

Por ejemplo, si los alumnos quieren mandar un tweet a su profesor, que está registrado en la red social con el alias de "Perezp", deberán escribir al principio de su mensaje el símbolo de @ seguido del respectivo alias (@Perezp).

Siguiendo con el mismo ejemplo, si el profesor publicase en su tablón un tweet y a algún alumno le gustase o le pareciera interesante, tiene la opción de poder retweetear ese mensaje. Con ello, lo que se consigue es que ese tweet quede reflejado en el muro de la otra persona, en este caso, en el del alumno.

También puede darse el caso de que el alumnado en un momento determinado quiera dirigirse a su profesor de manera privada. Para estas circunstancias Twitter dispone de Direct Message (DM). Quienes quieran mandar mensajes directos a alguien lo podrán hacer a través de dos vías. La primera (sea desde el ordenador o el móvil), escribiendo d espacio seguido del @username al que vaya dirigido y el mensaje (d pedro hola), o bien, directamente desde la opción de mensajes.

Otro concepto es \#hashtag (hash significa almohadilla (\#) y tag etiqueta). Éstas son, por tanto, etiquetas que las personas asignan a ciertos temas que consideran de interés; al acceder a ellos, se muestra una lista de tweets relacionados con ese tema y escritos por distintos usuarios.

Por ejemplo, el profesor de música publica en su Twitter el siguiente mensaje: Hoy hemos tocado la flauta en música y ha sido muy divertido \#MeGustaLaMúsica.

El hashtag llamado \#MeGustaLaMúsica les servirá a los alumnos para dejar sus opiniones y sentimientos respecto a la música.

Pero si contar lo que estás haciendo o pensando fuera su única utilidad, no animaría a usarlo en la escuela. Gracias a su facilidad de uso, el número de usuarios ha crecido y también las funcionalidades que estos mismos usuarios le han dado. J. J de Haro (2009), por ejemplo, habla del uso de Twitter en los centros como herra- 
mienta de comunicación para dar información a alumnos y familiares. Este autor indica:

El microblogging, como se denomina el uso de mensajes cortos de Twitter y otros servicios similares, puede aportar una serie de beneficios para el Centro:

- Disponer de un medio de comunicación vivo, en tiempo real, y eminentemente práctico para toda la comunidad educativa.

- Sentimiento de cercanía de los usuarios con respecto al Centro.

- Imagen de un Centro que se preocupa por sus clientes en el día a día, algo que sin duda es muy apreciado por todos.

En cuanto a los usos concretos que puede tener en el centro, señala:

- Canal de noticias en tiempo real para la comunidad educativa. Por ejemplo: Aviso sobre la publicación de boletines informativos periódicos.

Informaciones del momento, como fotografías publicadas en Internet, actualizaciones de la web del Centro, publicaciones en el blog del Centro u otros medios.

Informaciones de carácter más oficial, como becas, fechas de exámenes, etc.

Como agenda y recordatorio de eventos tales como reuniones o encuentros.

- Establecer una comunicación bidireccional entre el centro y la comunidad educativa. A diferencia de un foro de discusión, el alcance de Twitter está restringido a los seguidores de cada usuario, por lo que estas conversaciones tienen un alcance mucho más limitado. Así pues, Twitter está especialmente indicado para los Centros con miedo a establecer un diálogo público.

- Establecer un canal de noticias en diferido mediante el uso de los widgets que permiten publicar la información de Twitter en las páginas web. Twitter tiene sus propias utilidades, pero se pueden utilizar otras de terceros. Esto permite aumentar la visibilidad de las actividades del Centro.

Además de ciertas técnicas y consejos, indica errores que deben evitarse:

- Utilizarlo como medio de comunicación exclusivamente unidireccional, de uno hacia muchos. Se debe estar dispuesto a mantener un diálogo con los seguidores.

- Usar Twitter únicamente como un medio automatizado para distribuir noticias. Si detrás de la cuenta no hay personas, sólo se conseguirá que sea considerado una fuente de spam por sus seguidores. Desgraciadamente algunos centros abusan de servicios automáticos para la redifusión de noticias, como twitterfeed, y su cuenta twitter está totalmente deshumanizada. Esto influye negativamente en la imagen del Centro.

- Durante la marcha del curso evitar estar más de dos o tres días sin dar señales de vida ya que se puede transmitir una imagen de desidia y abandono muy negativa. 
Otra propuesta de uso de Twitter, para niños de primaria, se encuentra en un artículo de C. Ricardo Barreto y A. Chavarro (2010), y consiste en utilizar esta red social para comunicarse con niños de distintos países. Los alumnos tendrán que explicar, por medio de mensajes cortos o tweets, cómo se lleva a cabo una jornada escolar en sus respectivos centros educativos, es decir, qué asignaturas tienen, qué tipo de actividades realizan en cada una de ellas, a qué juegan en el recreo... Con estudiantes de cursos más avanzados, se puede usar para investigar sobre un tema propuesto y compartir con los compañeros enlaces de interés. También puede usarse para una lluvia de ideas.

En general, podemos decir que Twitter en la enseñanza permite ${ }^{6}$ :

- Investigación colaborativa.

- Discusiones.

- Transmisión de indicaciones.

- Retroalimentación instantánea.

Algunos de sus usos concretos ${ }^{7}$ :

1-Tablón de anuncios- medio de comunicación entre profesores y estudiantes.

2-Hacer resúmenes- de un texto, capítulo, etc. Límite 140 caracteres.

3-Compartir enlaces- cada vez que descubren algo interesante, lo compartan.

4-Twitter al acecho- seguir a un personaje famoso y documentar su progreso.

5-El Tweet del tiempo- elegir una persona famosa del pasado y crear una cuenta de Twitter para ella.

6-Micro Encuentros- mantener conversaciones en las que participen los estudiantes con cuenta en Twitter.

7-Micro Escritura-escritura progresiva y colaborativa para crear microrrelatos.

8-Lingua Tweeta- para el aprendizaje de idiomas modernos.

9-Tweming- comenzar un meme ${ }^{8}$ (de acuerdo a una etiqueta única precedida por \#) para que todo el contenido creado sea capturado automáticamente por Twemes $\mathrm{u}$ otro agregador.

6 Véase “Twitter en la investigación escolar", en http://cienciaescolar.net/proyectos $/ ?$ tag=papel

7 Véase "Usos de Twitter", 2009, en http://www.educacontic.es/blog/usos-de-twitter-eneducacion-0 (usos tomados de S. Wheeler: "Teaching with Twitter", 2009, en http://stevewheeler.blogspot.com/2009/01/teaching-with-twitter.html

${ }^{8}$ Un meme es, en las teorías sobre la difusión cultural, la unidad teórica de información cultural transmisible de un individuo a otro, o de una mente a otra, o de una generación a la siguiente. Es un neologismo acuñado por Richard Dawkins en El gen egoísta (The Selfish Gene), por la semejanza fonética con «gene» — gen en idioma inglés - y para señalar la similitud con «memoria» y «mimesis». http://es.wikipedia.org/wiki/Meme 
10-Twitter Pals- encontrar un Twitter penpal y conversar regularmente con ellos durante un período de tiempo para conocer su cultura, aficiones, amigos, etc.

Diversos usos son presentados también por S. Landete $(2009)^{9}$ :

Aparte de los usos obvios del microblogging de crear una comunidad, compartir links interesantes y recordar fechas de exámenes, deberes, etc., podemos usarlo para lo siguiente:

1. Tweets históricos. Preguntar a los alumnos qué escribirían en Twitter personajes históricos de relevancia en momentos históricos. Ejemplo: ¿Qué "twittearía" Camilo José Cela la noche antes de recibir el premio Nobel en 1989? ¿Qué escribiría Colón el 12 de Octubre de 1492? - recordar que el límite son 140 caracteres.

2. Monitorizar los tweets relacionados con términos de interés. Twitterfall nos muestra todos los tweets en los que aparecen las palabras que queramos, actualizándose en tiempo real. Por ejemplo, podemos ver todos los tweets en los que aparezca la palabra "zapatero", "rajoy", "crisis", "literatura", "astronomía", "física", etc.

3. Resumen. Pide a los alumnos que lean un artículo y lo resuman en un tweet.

4. Escritura creativa / debate. Se escribe en Twitter el comienzo de una historia y se deja que los alumnos la continúen. No se puede escribir de nuevo hasta que no hayan escrito todos. Para esto se debe acordar un "tag" común (los tags son 4 o 5 caracteres que comienzan por "\#" y sirven para identificar tweets relacionados al empezar todos los posts con la misma clave, facilitando búsqueda e identificación). Se puede utilizar la misma técnica para un debate.

5. Recoger opiniones sobre un tema de toda la clase. Se crea una cuenta de twitter asociada con el tema del que se quiere saber la opinión, y se pide a los alumnos que escriban a ese twitter sobre ese tema. Por ejemplo, la cuenta puede ser CambioClimat. En esa cuenta se recibirán automáticamente todos los posts que empiecen con la clave@CambioClimat, y la página http://twitter.com/CambioClimat recogerá todos los tweets de la clase.

6. Comunicar a los padres la marcha de la clase. Se crea una cuenta especial (para no mezclar identidades) y se pone en conocimiento de los padres.

7. Encuesta con Twitter. Conoce la opinión de la clase sobre un tema a través de twtPoll .

8. Desarrollo de empatía y estudio literario. Mientras están leyendo un libro, se pide a los alumnos que creen una cuenta de Twitter del personaje principal y vayan escribiendo posts conforme la novela avance como si fueran el prota-

${ }^{9}$ Véase una web-bibliografía sobre usos y aplicaciones de Twitter para la educación en http://www.vidadigital.net/blog/2009/06/28/web-bibliografa-sobre-aplicaciones-eimplicaciones-de-twitter-para-la-educacin-actualizada/

También, http://edutwitter.com/, comunidad educativa sobre Twitter. 
gonista. Puntos extra si lo hacen usando el mismo vocabulario que en la lectura.

9. Conceptos y vocabulario. Puedes postear una palabra y pedir su definición, sinónimos, antónimos. También se pueden postear letras y ver cuántas palabras distintas se pueden formar, o usar twtPoll para que los alumnos elijan entre varias posibles definiciones de un concepto a estudiar, y luego ver cuántos han acertado.

10. Reunir datos del mundo real. Las respuestas que obtenemos son siempre actuales y procedentes de otras personas con verdaderas historias detrás. Preguntas que se pueden lanzar en twitter para analizar las respuestas, por ejemplo: "¿Es la tecnología un puente entre el primer y el tercer mundo o una barrera?", "¿Qué acontecimientos precipitaron la $2^{a}$ guerra mundial?", "¿Con qué programas libres puedo sustituir el Notepad de Windows?", "¿Quién debería ser el próximo premio Nobel de...?".

Copiando el modelo de Twitter, han surgido otros servicios de microblogging destinados a la educación, por ejemplo, Edmodo (www.edmodo.com), especialmente creado para profesores y alumnos (hay grupos creados por el profesor donde se apuntan los alumnos, se pueden mandar mensajes a varios grupos a la vez, permite incrustar objetos como vídeos, adjuntar fotos o documentos, eventos, tareas, alertas, avisa de nuevos mensajes por twitter o correo electrónico, etc. ${ }^{10}$ ).

\subsection{Facebook}

Facebook es, en la actualidad, la red social con mayor extensión y repercusión mundial que existe. Según los últimos estudios y sondeos realizados sobre la misma, se dice que aproximadamente seiscientos millones de usuarios la utilizan como hilo conductor para comunicarse entre sí. Es difícil dar una cantidad exacta, ya que tiene gran actividad de registros diarios, es decir, de nuevos usuarios.

La sociabilidad se construye en Facebook por medio de una estrategia que conecta a los usuarios no solo entre sí, sino con numerosos círculos de sub-networks, eventos y grupos.

Una vez que el usuario se da de alta en Facebook (a través de una cuenta de correo electrónico), podrá ver en la pantalla principal su perfil (con datos de interés

\footnotetext{
${ }^{10}$ Otros servicios de microblogging para educación, tales como friendfeed, redalumnos, teambox..., pueden verse en http://edutwitter.wikispaces.com/Servicios $+\mathrm{de}+$ microblogging+educativo

Diversas experiencias con microblogging, agrupadas por nivel, pueden encontrarse en http://edutwitter.wikispaces.com/Experiencias+de+clase+con+Microblogging

Lista de centros que usan Twitter: http://edutwitter.wikispaces.com/Centros+educativos + en+Twitter

Docentes que usan Twitter: http://edutwitter.wikispaces.com/Docentes+en+Twitter
} 
personal, etc.) y su tablón o muro destinado a escribir sus propios comentarios y ver reflejados en él los que sus amigos dejen publicados.

Además de mensajes escritos, Facebook da la posibilidad de publicar fotos, vídeos y enlaces a otras páginas web, y también nos permite comunicarnos con otras personas a través del servicio de mensajería instantánea, más comúnmente llamado chat.

\subsection{1. ¿Cuáles son sus ventajas más significativas?}

Está disponible en más de cien idiomas, lo que hace que se convierta en una red social al alcance de todas las personas que se encuentren en cualquier parte del mundo.

Permite a los docentes saber más sobre intereses y aficiones de sus alumnos, ya que éstos tienen un perfil en donde quedan reflejados.

Esta red social hace que el proceso de enseñanza y aprendizaje se convierta en una forma de llevar la enseñanza de manera innovadora, creativa y entretenida.

El administrador de un grupo de trabajo recibirá en su correo electrónico (si así lo considera) todas las notificaciones que los alumnos vayan publicando en él.

En Facebook existe la opción de "configurar la privacidad" de la cuenta según el usuario desee. En este caso, al estar trabajando con alumnos, se les enseñará a privatizar su cuenta para que solamente el grupo de compañeros y el profesor accedan a la información.

\subsection{2. ¿De qué servicios de Facebook se puede beneficiar un docente para enseñar?}

Pueden encontrarse diversas experiencias de uso de Facebook, por ejemplo, en la Universidad de Cataluña, en el 2010 el grupo Web2Learn examinó el potencial de Facebook para crear actividades colaborativas. Algunas de las actividades llevadas a cabo fueron (F. Llorens y N. Capdeferro, 2011: 200):

-Estimular el desarrollo de habilidades técnicas y sociales básicas para participar en la red social en particular, y en la sociedad contemporánea en general (crear cuentas individuales, crear un espacio social para llevar a cabo actividades colaborativas).

-Promover el aprendizaje y trabajo entre pares (peer-to-peer): proponer estrategias, recursos y fuentes de información a los otros miembros del grupo, en conexión con el uso educativo de Facebook y su potencial como apoyo para el trabajo colaborativo.

-Producir conocimiento en el proceso de colaboración con los otros miembros del grupo (documentar el proceso de trabajo usando herramientas externas en for- 
matos visual y escrito: texto, vídeos, presentaciones, mind maps...), usar servicios externos de almacenaje (GDocs, Scribd...).

-Evaluar el potencial del ambiente elegido como medio de trabajo colaborativo y autoevaluar el trabajo del grupo (elaborar un mapa mental que refleje los resultados, actividades realizadas y conclusiones del grupo).

Este grupo de trabajo ve como ventajas de facebook para el trabajo colaborativo la simplicidad y la rapidez para administrar el trabajo en grupo; la sencillez para usar herramientas como el foro, el tablón, fotos, etc.; el alto grado de conectividad externa; el que pueda usarse en móviles y con muchos sistemas operativos... (pp. 202, 203).

Como fallos estarían la presencia de elementos de distracción tales como anuncios, sugerencias, peticiones...; el carecer de un verdadero sistema de etiquetas, filtros, búsquedas y organización de la información; la excesiva simplicidad de los tableros de discusión; no poder conversar en tiempo real con audio y vídeo... (pp. 203, 204)

Pero, en general, podemos decir que Facebook potencia la creación de una comunidad cultural virtual y un aprendizaje social. Interaccionando en relación a un objetivo o tópico compartido, se generan enlaces interpersonales de confianza y apoyo.

It fosters a virtual community culture and social learning. From a pyschosociological viewpoint, this culture is rooted in values that emerge from the users, who interact in the network on a shared objective or topic, and generate interpersonal links of trust and support, as well as feelings of belonging and social identity. Furthermore, the existence of exchange networks and information flows is a significant aspect when it comes to shaping and maintaining a social network. The importance of collaboration should be underscored (Prendes, $2003^{11}$ ): the objective is to create a 'shared experience' rather than an 'experience that is shared'. (F. Llorens y N. Capdeferro, 2011: 205, 206)

Además de esto, potencia las formas de aprendizaje innovador. Se trata de un aprendizaje informal ${ }^{12}$ que hace que se construya el conocimiento y se desarrollen habilidades. También, motiva a los estudiantes puesto que las generaciones jóvenes

\footnotetext{
${ }^{11}$ M. P. Prendes: “Aprendemos... ¿cooperando o colaborando? Las claves del método”, en F. Martínez (coord..), Redes de comunicación en la enseñanza, Barcelona, Paidós, 2003.

12 Aprendizaje formal es aquel aprendizaje que un centro educativo pone en marcha de manera estructurada (objetivos, contenidos, metodología...), siendo de carácter intencional por parte del alumnado. Aprendizaje informal es otro tipo de aprendizaje que se obtiene a través de las actividades del día a día, teniendo relación con el ocio y el trabajo que cada persona desempeñe. Este aprendizaje puede ser intencional, pero la mayoría de las veces no lo es.
} 
están muy interesadas en usar nuevas tecnologías y en compartir información. Parece que hace aumentar la autoestima de muchos estudiantes, estimula la creatividad y resulta en un aprendizaje más espontáneo y divertido.

Hace, además, que el contenido sea presentado a través de materiales reales y apoya la comunicación sincrónica y asincrónica.

Esta red nos da la posibilidad de crear grupos de trabajo, por lo que será muy enriquecedor tanto para los docentes como para los discentes. El que a un profesor se le permita crear todos los grupos de trabajo que quiera para trabajar independientemente con cada uno de ellos, dará lugar a una mayor organización y coordinación.

Lo mismo sucede con el grupo de alumnos que tiene varias asignaturas. Estos podrán encontrar en su página principal diferentes grupos denominados con los nombres de las diferentes asignaturas.

En la imagen que aparece a continuación ejemplificamos cómo, una vez creada una cuenta de Facebook con el nombre "Río Deva" (nombre de un colegio inventado), podemos empezar a crear grupos de trabajo con los alumnos. Es tan sencillo como pinchar con el botón izquierdo del ratón en la opción "crear un grupo" y seguir los pasos que Facebook establece. Una vez hecho eso, tendremos que introducir un nombre para el grupo y agregar a los alumnos que se desee tener en él.

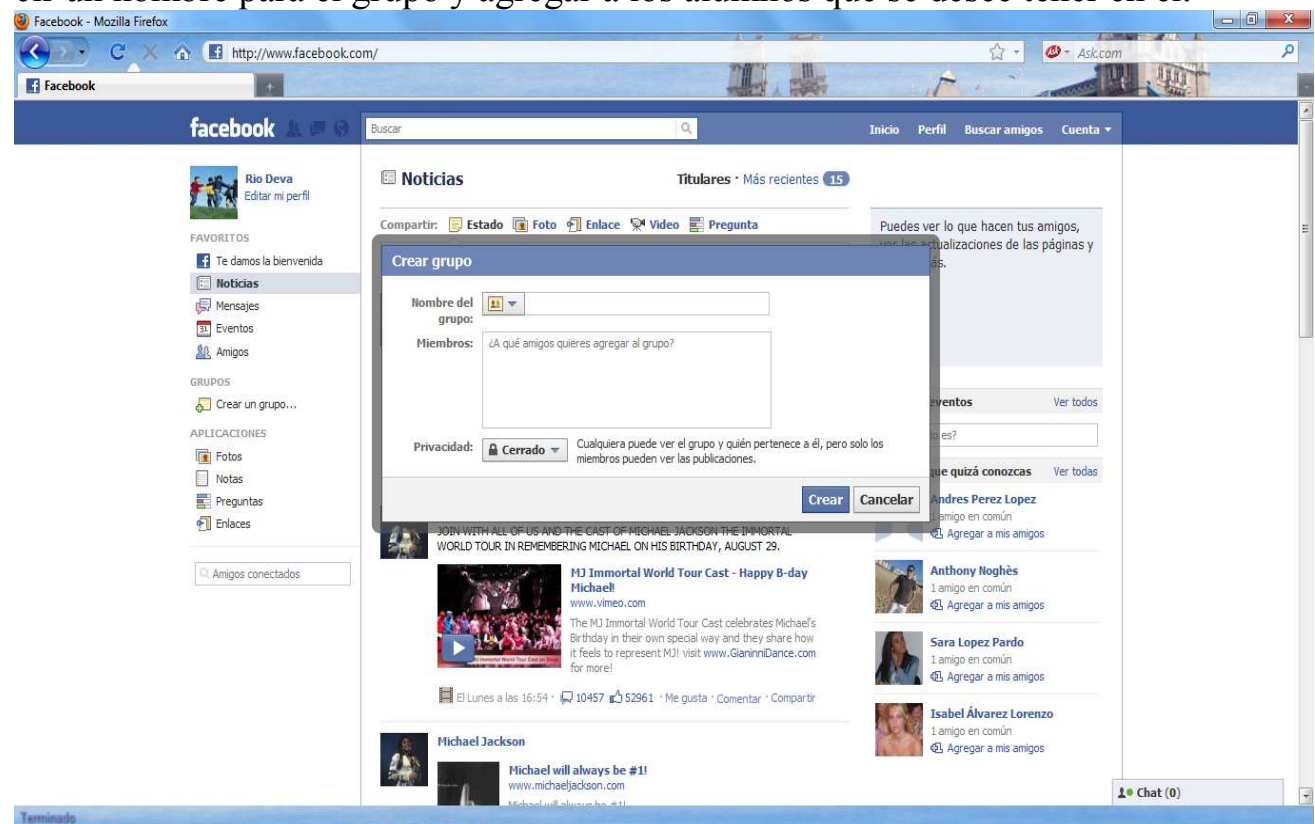

Dentro de este primer servicio que nos ofrece Facebook, existe la opción de crear documentos de texto y también de hablar a través de los chats grupales. La finalidad de estos chats es intercambiar información al instante entre el profesor y 
el alumno o entre los propios compañeros, ya que la duda que a uno se le pueda plantear respecto a alguna tarea en concreto, puede ser solucionada mediante la aportación y ayuda de otro compañero.

Facebook también nos ofrece una gran variedad de aplicaciones: SlideShare es una de ellas. Con esta herramienta tanto los docentes como los alumnos pueden publicar presentaciones sobre cualquier actividad o trabajo planteado desde Facebook.

Finalmente, hay destacar que esta red social nos da la posibilidad de crear páginas. Cuando un usuario crea una lo hace con la finalidad de que el resto de usuarios de Facebook la visiten y se beneficien de las aportaciones que se hagan en ella.

Resulta fácil también acceder a diferentes páginas desde Facebook. Simplemente, al escribir el nombre de la página en la opción "buscar" (página principal de Facebook), Facebook nos dará a elegir entre muchas relacionadas con lo que hayamos escrito, para que el usuario pueda escoger la que más le interese.

Por ejemplo, en la imagen siguiente se observa que hemos introducido la palabra "chocolate" y hemos obtenido una página. Si el usuario quiere estar al tanto de todas las novedades de esta página, solamente tendrá que pulsar sobre el botón izquierdo del ratón y marcar la opción "me gusta".

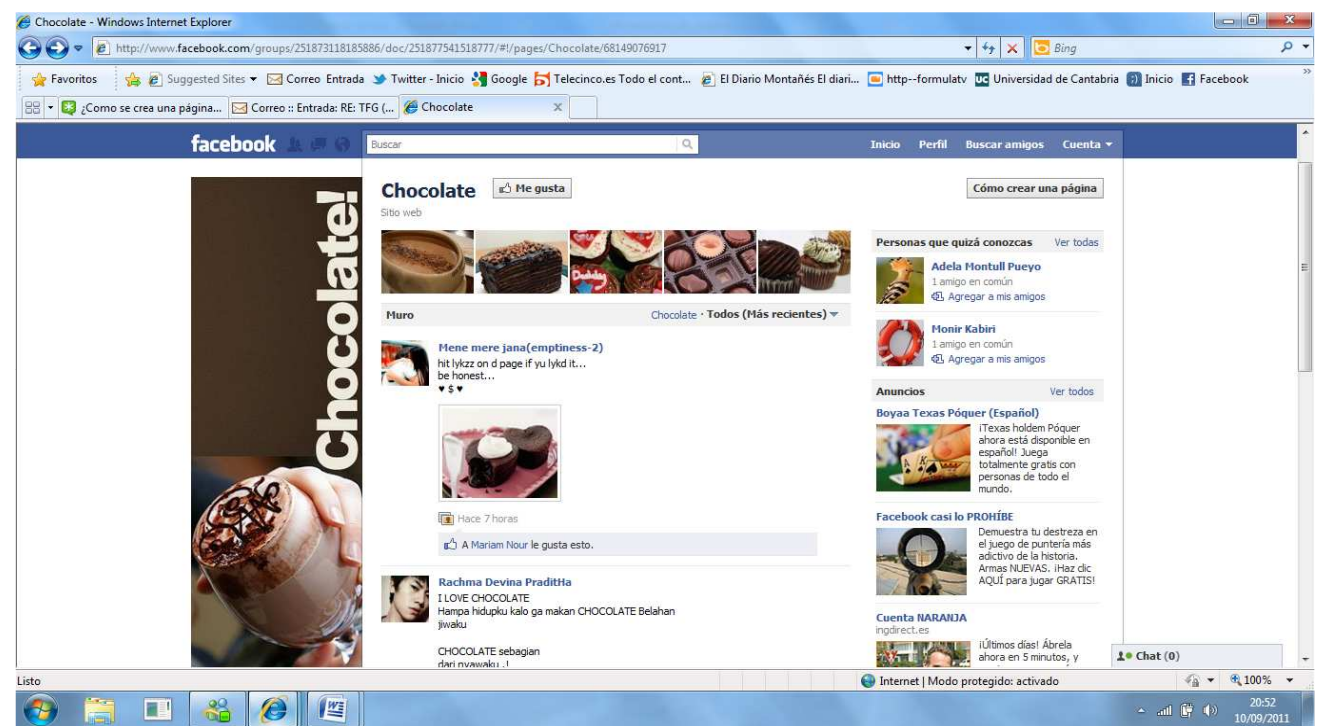

En la imagen anterior, si nos fijamos en la parte superior derecha, Facebook nos da la opción de crear nuestra propia página.

Una vez que estamos dentro de esta opción, se nos da la oportunidad de enmarcar nuestra futura página en diferentes categorías según las características de la misma, como vemos a continuación: 


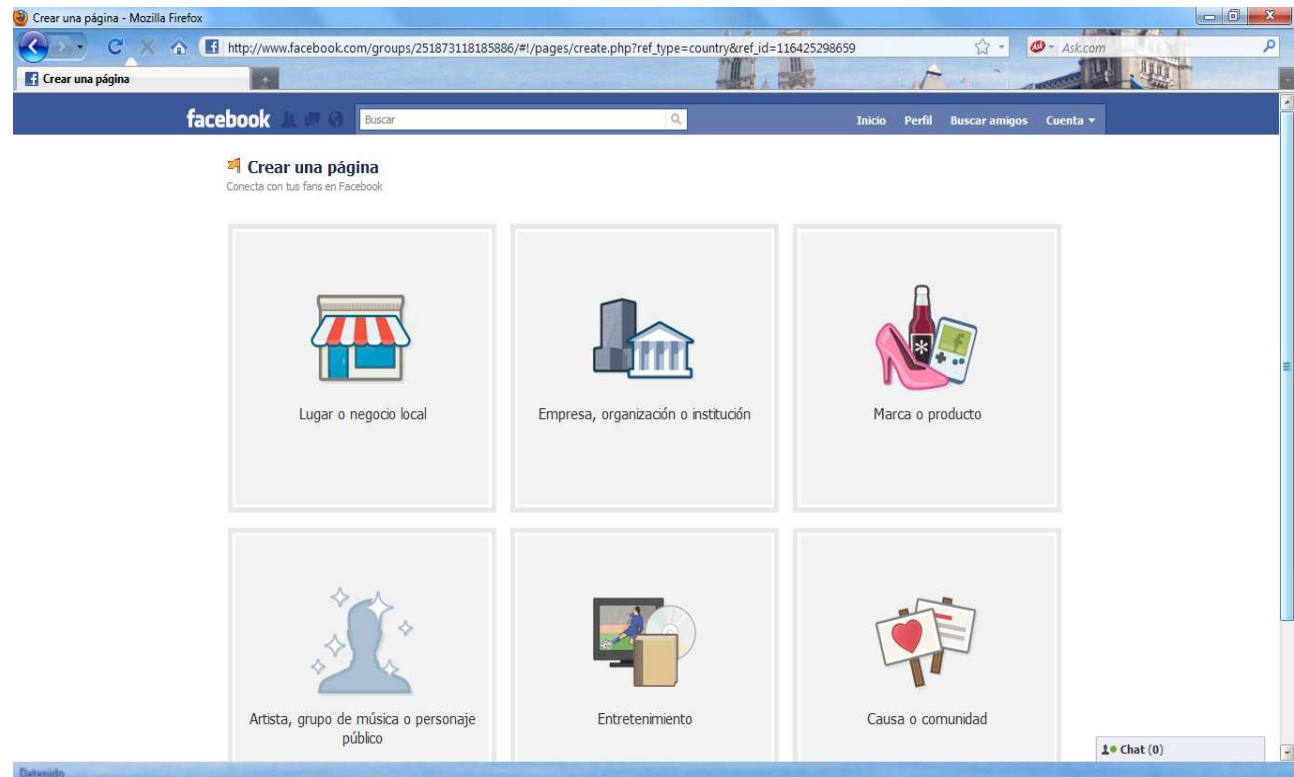

\subsection{Objetivos}

Los objetivos que tienen las actividades que posteriormente plantearemos son:

- Llevar a cabo aprendizajes colaborativos a través de equipos de trabajo.

- Fomentar la iniciativa y la autonomía personal de los alumnos a través de Facebook y Twitter.

- Estar en contacto con las familias de los alumnos a través de las redes sociales.

- Mejorar la relación profesor-alumno a través de la comunicación con estos medios tecnológicos tan innovadores.

- Ver de manera más próxima la relación entre el aprendizaje formal e informal del alumnado, ya que, hasta ahora, es habitual que no haya ninguna relación entre uno y otro.

- Trabajar materias que son comunes a todas las áreas curriculares, como la lectura y la escritura.

\subsection{Usos y actividades}

Antes de exponer las actividades que se han planteado, es importante tener en cuenta que, cuando un profesor toma la decisión de utilizar Facebook con su grupo de alumnos, es recomendable utilizar la cuenta de Facebook del centro educativo al que pertenece, ya que el uso va a ser con fines profesionales. 
En el caso de que el centro no esté registrado en Facebook, el docente deberá crearse una cuenta destinada, única y exclusivamente, a aspectos académicos y dejar la suya personal, si la tiene, al margen.

Esto se relaciona con el debate de si los docentes tienen que ser amigos o no de sus alumnos a través de las redes sociales. Existen infinidad de opiniones, pero lo que verdaderamente nos interesa a quienes nos dedicamos a la enseñanza es que las redes sociales son una herramienta a través de la cual tenemos la oportunidad de conocer más en profundidad a nuestros alumnos, en el sentido de saber sus intereses, opiniones, etc.

A continuación, se van a plantear diferentes actividades tanto con Facebook como con Twitter, todas ellas relacionadas con el área de Lengua Castellana y Literatura (aunque se podrían utilizar en el resto de materias).

La primera de ellas consiste en la creación, por parte del docente, de un grupo de trabajo en Facebook denominado con el nombre de la asignatura en concreto.

Cuando el maestro ya tiene creado un grupo, podrá hacer en él actividades y también lo podrá dedicar para otros usos, por ejemplo, ponerse en contacto con las familias de sus alumnos a través de documentos de texto. A través de ellos se les puede informar sobre reuniones o sobre el programa o guía didáctica de la asignatura de Lengua Castellana (en donde quedan reflejados los objetivos, contenidos, evaluación, etc.), evitando, de esta manera, las cartas impresas.

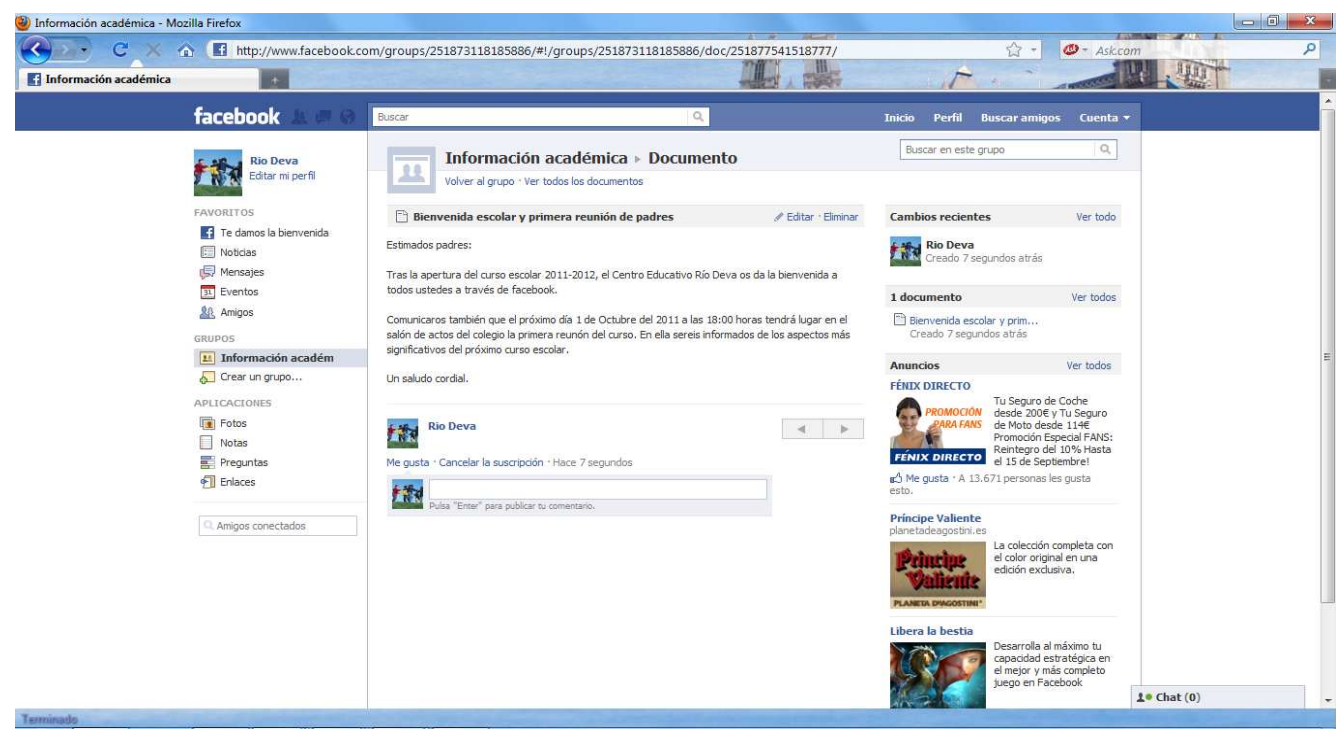

En la imagen anterior se observa que, a través de un grupo denominado "Información académica", se puede informar a los padres y alumnos de diferentes aspectos educativos. En este caso he escrito una noticia en un documento de texto, 
con dos objetivos muy concretos: dar la bienvenida a las familias al curso académico 2011-2012 y citarles para una reunión de principio de curso. Así quedó reflejado en la red social:

\section{Estimados padres:}

Tras la apertura del curso escolar 2011-2012, el Centro Educativo Río Deva os da la bienvenida a través de Facebook.

Queremos comunicaros también que el próximo día 1 de Octubre del 2011 a las 18:00 horas tendrá lugar en el salón de actos del colegio la primera reunión del curso. En ella seréis informados de los aspectos más significativos del próximo curso escolar.

Un saludo,

El tutor.

Esta propuesta, aunque no sea una actividad propiamente, es importante, ya que los alumnos han de ser lo suficientemente responsables para comunicar a sus familias las novedades que pueda haber en la red social.

Por ello, el maestro llevará a cabo la evaluación a través de una rúbrica:

\begin{tabular}{|c|c|c|c|}
\hline $\begin{array}{l}\text { Conoce Face- } \\
\text { book y Twitter } \\
\text { y muestra inte- } \\
\text { rés a la hora de } \\
\text { utilizarlas. }\end{array}$ & $\begin{array}{l}\text { Informa a su familia de } \\
\text { que tienen cartas in- } \\
\text { formativas importantes } \\
\text { dentro de la red social } \\
\text { (fomento de la respon- } \\
\text { sabilidad). } \\
\text { En este caso, habría que } \\
\text { contactar con los padres } \\
\text { de alguna manera (a } \\
\text { través de la misma red } \\
\text { o de una carta que han } \\
\text { de firmar) para saber } \\
\text { que están informados. }\end{array}$ & $\begin{array}{l}\text { Accede con frecuencia } \\
\text { a la red social para ver } \\
\text { las publicaciones que } \\
\text { el profesor establece } \\
\text { para poder comunicár- } \\
\text { selo a sus padres. }\end{array}$ & $\begin{array}{l}\text { Se le ve con moti- } \\
\text { vación al manejar } \\
\text { las redes sociales y } \\
\text { con ganas de } \\
\text { aprender a través de } \\
\text { ellas. }\end{array}$ \\
\hline $\begin{array}{l}\text { SI / NO / A } \\
\text { VECES }\end{array}$ & SI / NO / A VECES & SI / NO / A VECES & SI / NO / A VECES \\
\hline
\end{tabular}

Otra actividad que se podría realizar tanto con Twitter como con Facebook consistiría en que los alumnos, al finalizar su horario escolar, escribiesen desde sus propios ordenadores lo realizado a lo largo de la jornada escolar. 


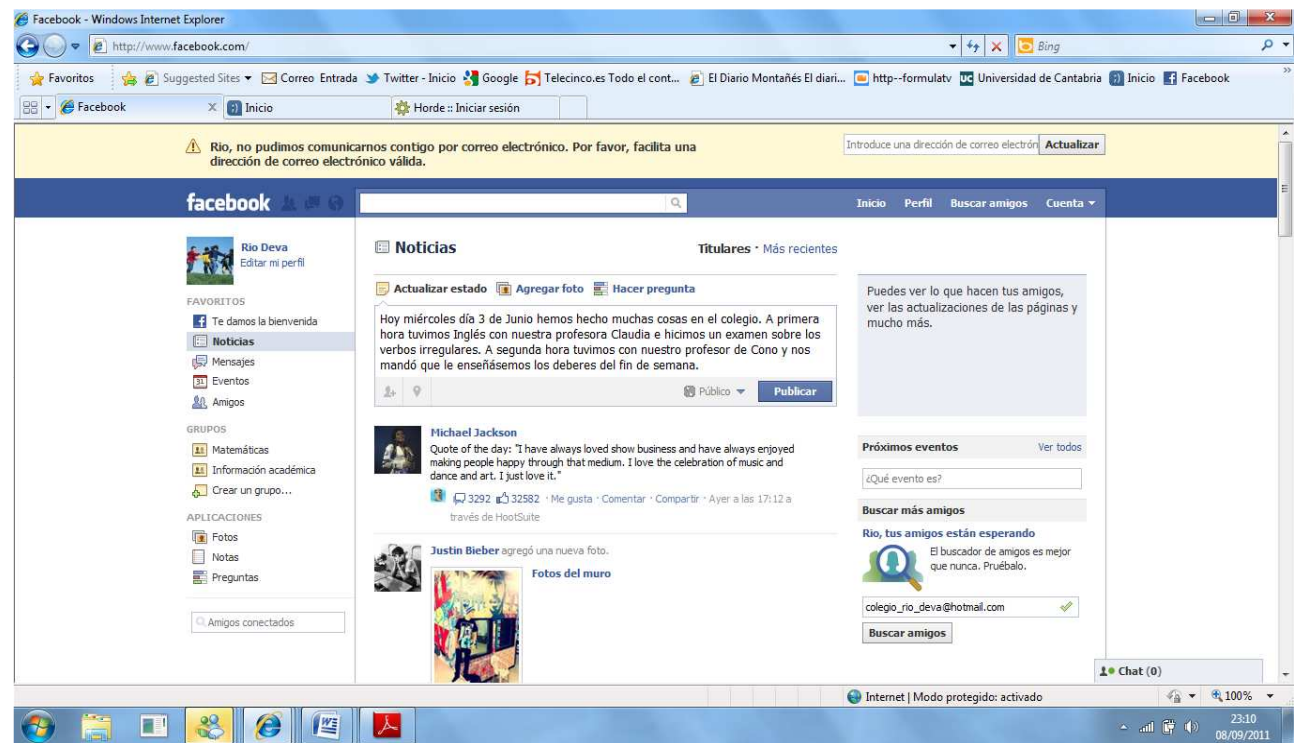

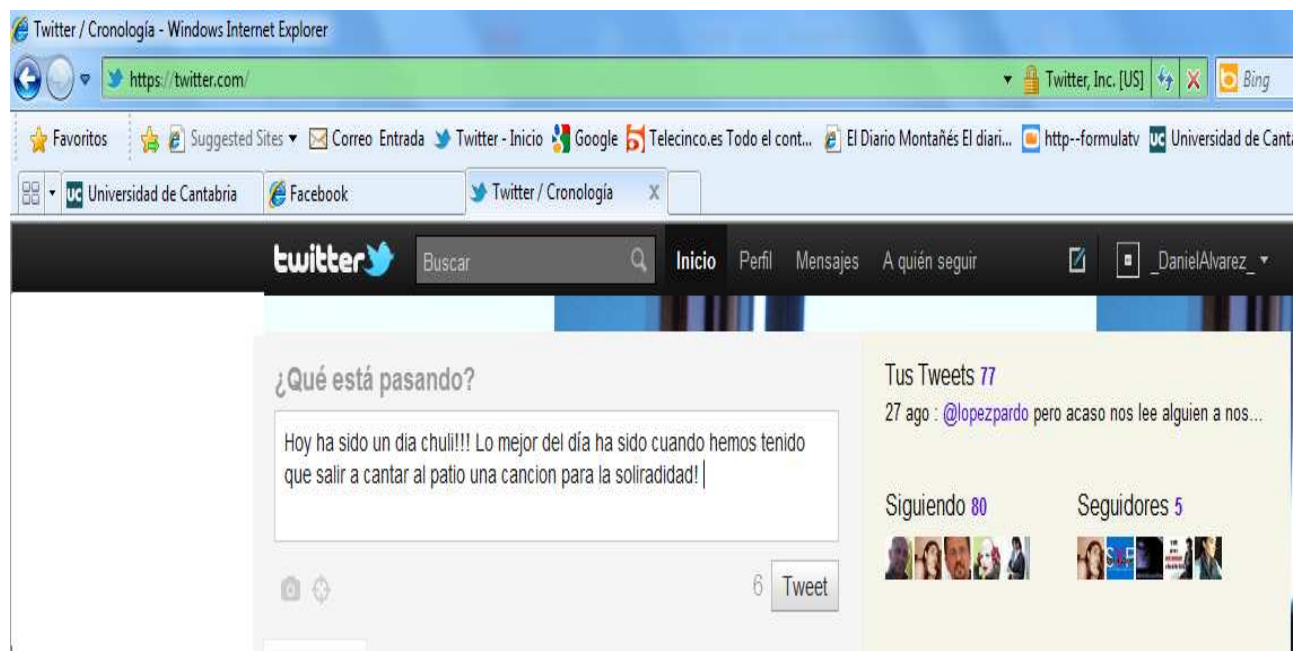

En las dos imágenes anteriores podemos observar lo mismo. Tanto en la primera (Facebook) como en la segunda (Twitter), finjo ser un alumno de primaria escribiendo en su muro o tablón:

Hoy miércoles día 3 de junio hemos hecho muchas cosas en el colegio. A primera hora tuvimos inglés con nuestra profesora Claudia e hicimos un examen sobre los verbos irregulares. A segunda hora tuvimos con nuestro profesor de Cono y nos mandó que le enseñásemos los deberes del fin de semana... 
Hoy ha sido un día chuli!!!... (Podemos usar las redes sociales para enseñar a los alumnos la diferencia entre lenguaje formal e informal y el tipo de expresiones y recursos que caben en una y otra).

La rúbrica correspondiente a esta actividad ya incorpora calificaciones:

\begin{tabular}{|l|l|l|l|}
\hline Insuficiente & Suficiente & Notable & Sobresaliente \\
\hline $\begin{array}{l}\text { No elabora un } \\
\text { diario, sino que } \\
\text { solo enumera } \\
\text { actividades que } \\
\text { ha ido haciendo } \\
\text { a lo largo del } \\
\text { día. }\end{array}$ & $\begin{array}{l}\text { Realiza el diario } \\
\text { pero no profundiza } \\
\text { del todo en los as- } \\
\text { pectos más impor- } \\
\text { tantes del día; lo } \\
\text { hace de manera } \\
\text { general. }\end{array}$ & $\begin{array}{l}\text { Hace una descrip- } \\
\text { ción de todos los } \\
\text { aspectos realizados } \\
\text { durante la jornada } \\
\text { escolar, con cierto } \\
\text { grado de elabora- } \\
\text { ción previa. }\end{array}$ & $\begin{array}{l}\text { Antes de empezar con la } \\
\text { descripción ha realizado } \\
\text { un guión (a modo de } \\
\text { esquema) en el que ha } \\
\text { ido apuntando todo lo } \\
\text { realizado en clase, vién- } \\
\text { dose reflejado poste- } \\
\text { riormente en la forma de } \\
\text { redactarlo o a la hora de } \\
\text { poner ejemplos. }\end{array}$ \\
\hline
\end{tabular}

Otra actividad que podemos realizar con Facebook consistiría en que, al acabar un tema de Lengua Castellana y Literatura, el docente forme grupos con el propósito de buscar información sobre diferentes aspectos, para después compartirla con los demás a través de enlaces en el muro o tablón del grupo.

Los grupos serán de pocos miembros, de acuerdo con lo establecido por el aprendizaje colaborativo.

Por ejemplo, si en el aula se están dando las reglas de ortografía, los alumnos podrán subir a Facebook información que tenga relación con ello.

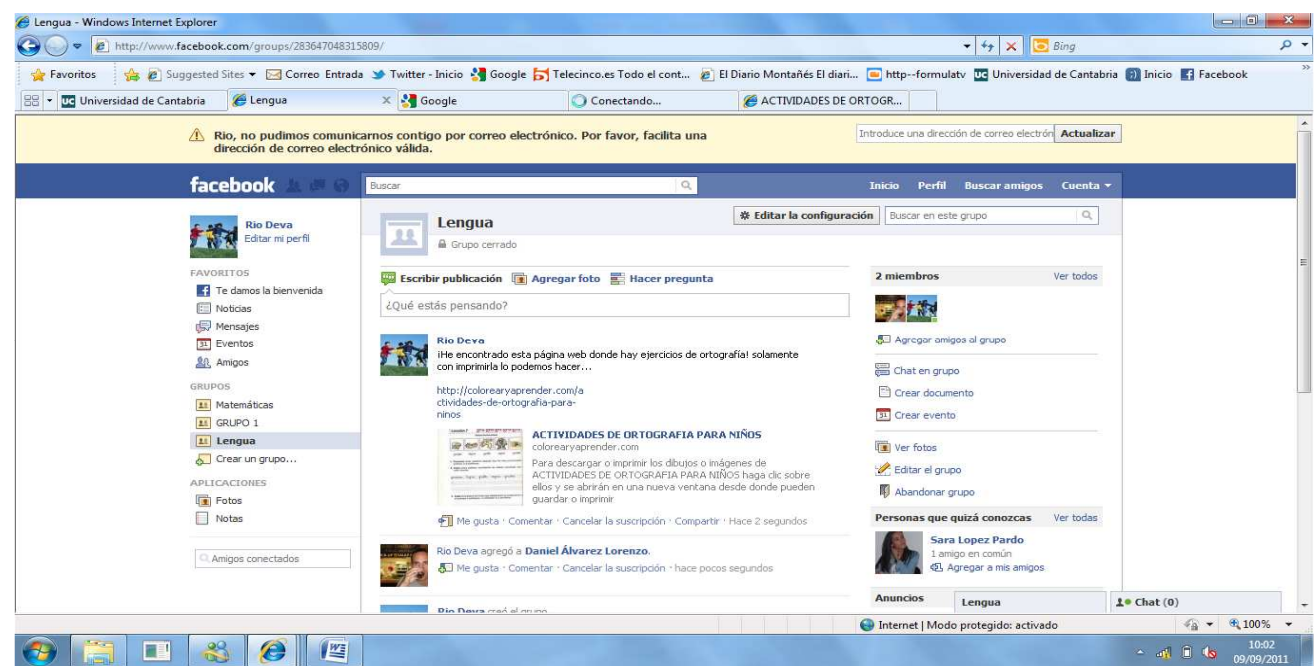


En la imagen anterior simulo cómo un alumno deja publicado en el muro del grupo denominado "Lengua" un enlace a una página web en la que se pueden realizar actividades de ortografía (http://colorearyaprender.com/actividades-deortografia-para-ninos). Las hojas de ejercicios tendrán que imprimirse, ya que después se entregarán al profesor y se guardarán en el archivador de clase.

La rúbrica correspondiente a esta actividad es la siguiente:

\begin{tabular}{|c|c|c|c|}
\hline Insuficiente & Suficiente & Notable & Sobresaliente \\
\hline $\begin{array}{l}\text { No accede a la red } \\
\text { social, por lo que no } \\
\text { publica ningún } \\
\text { enlace ni deja co- } \\
\text { mentarios. El } \\
\text { alumno muestra } \\
\text { cierto desinterés. }\end{array}$ & $\begin{array}{l}\text { Publica enlaces y } \\
\text { comentarios pero a } \\
\text { veces la información } \\
\text { no es lo suficiente- } \\
\text { mente enriquecedora } \\
\text { para los demás. }\end{array}$ & $\begin{array}{l}\text { Los comentarios y } \\
\text { enlaces relaciona- } \\
\text { dos con los conteni- } \\
\text { dos del temario son } \\
\text { publicados y de- } \\
\text { muestra que el } \\
\text { alumno ha hecho } \\
\text { una buena selec- } \\
\text { ción. }\end{array}$ & $\begin{array}{l}\text { Hace publicaciones } \\
\text { que demuestran } \\
\text { cierto grado de ma- } \\
\text { durez. Además, } \\
\text { añade explicaciones } \\
\text { para que los compa- } \\
\text { ñeros se animen a } \\
\text { leer lo publicado. }\end{array}$ \\
\hline
\end{tabular}

Finalmente, puede resultar interesante que los docentes en sus respectivas asignaturas marquen, junto a la opinión de sus alumnos, un día y una hora para resolver todas las dudas que les hayan podido surgir en relación a lo visto en clase. Esto se llevaría a cabo mediante el servicio de mensajería instantánea que ofrece Facebook (chat en grupo).

Dado que un maestro puede tener un gran número de alumnos por clase, podrá dividirlos en distintos grupos para que, de esta manera, a la hora de resolver dudas, no haya un cierto caos.

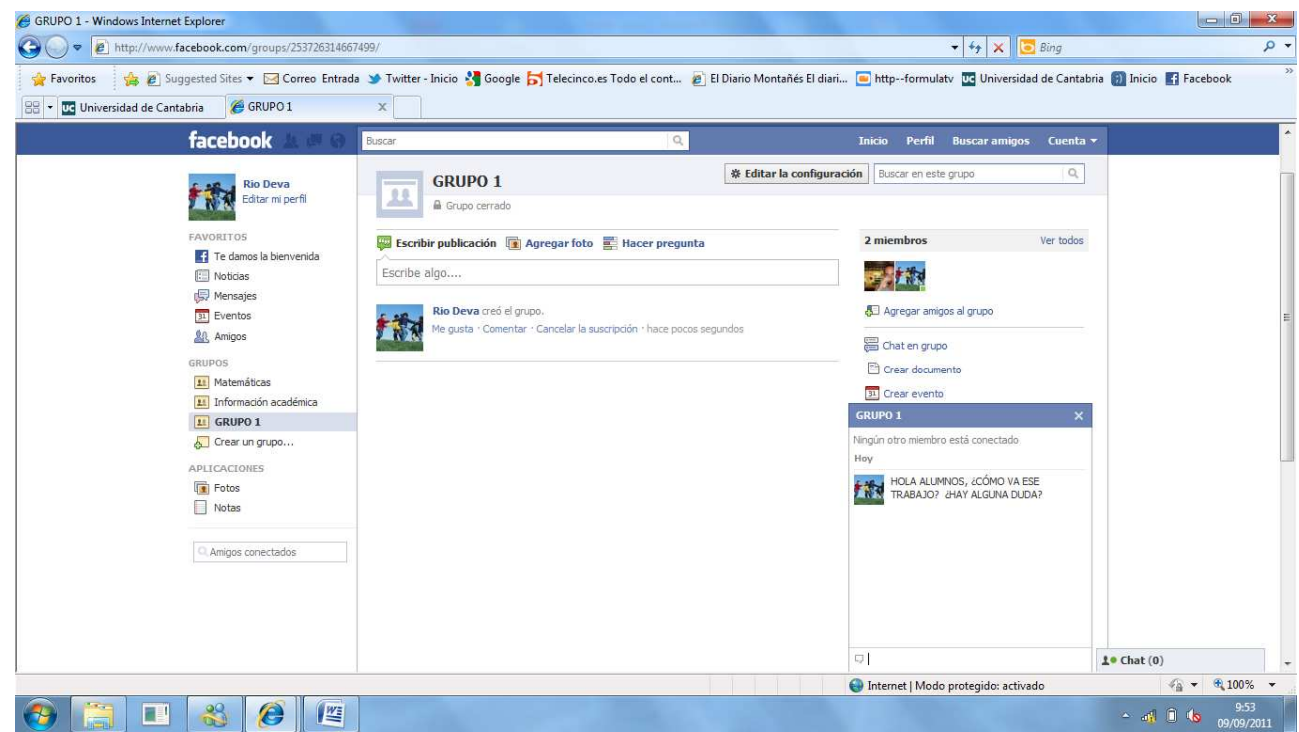


En cuanto a la actividad que se observa en esta imagen, me he hecho pasar por el profesor que accede desde la cuenta del centro para comunicarse con su grupo de alumnos 1 a una hora establecida con anterioridad. Se les manda trabajar en torno a un tema en concreto y de ahí el mensaje que escribimos en el chat: "Hola alumnos ¿Cómo va ese trabajo? ¿Hay alguna duda?”

En esta actividad se pretende que los alumnos vean que Facebook es algo más que una red social donde poder hablar con los amigos. Mediante las actividades o propuestas que he señalado, los alumnos tienen que darse cuenta de que es una plataforma en la cual pueden trabajar, aprender y divertirse.

Rúbrica:

\begin{tabular}{|l|l|l|l|}
\hline Insuficiente & Suficiente & Notable & Sobresaliente \\
\hline $\begin{array}{l}\text { No muestra } \\
\text { interés en esta } \\
\text { aplicación, por } \\
\text { lo que no acce- } \\
\text { de a ella cuando } \\
\text { se le manda. }\end{array}$ & $\begin{array}{l}\text { Asiste regularmen- } \\
\text { te a las reuniones } \\
\text { en el chat y expone } \\
\text { sus dudas, pero } \\
\text { estas suelen ser } \\
\text { poco profundas y } \\
\text { muy generales, sin } \\
\text { ahondar en aspec- } \\
\text { tos específicos. }\end{array}$ & $\begin{array}{l}\text { Plantea al profesor } \\
\text { preguntas con cierto } \\
\text { grado de concreción, } \\
\text { lo que demuestra que } \\
\text { el alumno se preocu- } \\
\text { pa por aprender a } \\
\text { través de esta herra- } \\
\text { mienta. }\end{array}$ & $\begin{array}{l}\text { Tiene siempre preguntas } \\
\text { planteadas para hacérse- } \\
\text { las llegar al profesor a } \\
\text { través del chat grupal, lo } \\
\text { que hace pensar que ese } \\
\text { alumno es responsable } \\
\text { con su proceso de ense- } \\
\text { ñanza y aprendizaje. } \\
\text { Además, se preocupa de } \\
\text { ayudar al resto de com- } \\
\text { pañeros. }\end{array}$ \\
\hline
\end{tabular}

Evidentemente, en todas estas actividades hay que asegurarse de que el alumno tiene acceso a un ordenador y conexión a Internet, si es que las actividades van a realizarse fuera de la clase, ya sea en su casa o en un aula informática en el colegio o escuela. También, podemos destinar un tiempo dentro de la clase, si es que contamos con los medios necesarios en el centro. Esto último quizá sería lo más adecuado, ya que se trata de alumnos pequeños, y podemos así ayudarlos y controlarlos mejor.

\section{CONCLUSIONES}

Son innegables los grandes avances tecnológicos que se han producido en los últimos años y que han afectado a la vida diaria de las personas. Se trata de avances como el de la Web 2.0, que han cambiado la concepción de Internet y de la comunicación, que es ahora más interactiva y dinámica, y que hace que haya más facilidad para la conexión entre aquellos con los mismos intereses, y que se dé mayor importancia a los aportes de todos. La Web 2.0 supone una concepción activa del uso de Internet, y la creación continua de nuevas aplicaciones no hace sino darnos nuevas posibilidades en el E-learning. 
La Web 2.0 ha facilitado la aplicación de métodos de enseñanza como el aprendizaje colaborativo, basado en la interacción del alumno con el profesor y los compañeros, compartiendo información y generando así conocimiento. También se da una comunicación más rápida entre el profesor ( $\mathrm{y}$ el centro) y los padres, que pueden ver también lo que sus hijos hacen, a través de los blogs, de Facebok y de Twitter.

Estos avances tecnológicos son muy rápidos, por ello, los profesores hemos de actualizarnos constantemente, y ya no solo estar al día en el contenido de nuestra materia, sino en los medios para transmitirla, que también han de enseñarse a los alumnos. Y así lo requiere la LOE, en concreto en los objetivos para la educación primaria: "Iniciarse en la utilización para el aprendizaje de las tecnologías de la información y la comunicación, desarrollando el espíritu crítico ante los mensajes que se reciben y se elaboran".

Aunque es cierto que en muchos centros aún no se dispone de la estructura informática necesaria (Internet, pizarras digitales, ordenadores...) para incorporar las TIC en los procesos educativos, o los maestros no están formados, o no tienen tiempo para compatibilizar los objetivos educativos con la integración de las TIC. La LOE es un tanto general y tiene objetivos poco específicos en tecnología y es posible que esté alejada de la realidad escolar, por eso, los maestros tenemos que hacer un gran esfuerzo para que nuestros alumnos salgan preparados en este aspecto fundamental en el mundo tecnológico presente ${ }^{13}$.

13 También, las diferencias por países son acusadas; en España, el porcentaje de personas que usan el ordenador para el aprendizaje en educación primaria y secundaria obligatoria es solo el 1'6, mientras que es el 10'1 en Francia, el 11'3 en Finlandia, el 17'1 en Luxemburgo y el 17'7 en Suecia (datos del 2009).

En cuanto al número medio de alumnos por ordenador (curso 2007-2008), en primaria, encontramos un 7' 3 en los centros públicos ( $5^{\prime} 4$ en secundaria y FP), y un 11'2 en los privados. Las diferencias regionales son acusadas, pues mientras en Canarias el porcentaje para primaria es de un 15'4, en Aragón es un 3'6. (Véase Instituto de tecnologías educativas: "Indicadores y datos de las tecnologías de la información y comunicación en la educación en España y Europa”, 2010, en

http://recursostic.educacion.es/blogs/europa/media/blogs/europa/informes/Indicadores_y_d atos_de_las_TIC_en_la_\%20Educacion_en_Europa_y_Espana_ITE_2009.pdf

Véase también "Las TIC y la LOE", en http://www.ticyeducacion.com/2010/10/las-tic-y-laloe.html y "Las TIC en educación: coordinación y gestión de los recursos TIC en las zonas escolares", en http://late-dpedago.urv.cat/joomla2/images/unia/cinta.pdf 


\section{BIBLIOGRAFÍA}

AUNIÓN, J. A. (2009): "La era del profesor desorientado". El País, 18-7-2009. Disponible http://www.elpais.com/articulo/sociedad/era/profesor/desorientado/elpepusoc/2 0090718elpepisoc 5/Tes [Consulta: 17 de julio 2011]

BERNAZA RODRÍGUEZ, G., y LEE TENORIO, F. (2005): "El aprendizaje colaborativo: una vía para la educación de postgrado". Revista Iberoamericana de Educación, vol. 37, $n^{\circ}$ 3, 1-17. Disponible en: http://www.rieoei.org/deloslectores/1123Bernaza.pdf [Consulta: 2 de septiembre 2011]

CABERO, J. (2006): "Bases Pedagógicas del e-learning”. Revista de Universidad y Sociedad del Conocimiento, vol. 3, $\mathrm{n}^{\mathrm{o}}$ 1, 1-10. Disponible en: http://www.uoc.edu/rusc/3/1/dt/esp/cabero.pdf [Consulta: 14 de julio 2011]

CALZADILLA, M. ${ }^{\mathrm{a}}$ E. (2008): "Aprendizaje colaborativo y tecnologías de la información y la comunicación". Revista Iberoamericana de Educación. De los lectores. Disponible en: http://www.rieoei.org/deloslectores/322Calzadilla.pdf [Consulta: 24 de julio 2011]

CARRIÓ PASTOR, M. ${ }^{a}$ L. (2006): Aprendizaje colaborativo asistido por ordenador. Valencia: Blau Verd.

COLL, C., y MONEREO, C. (2008): Psicología de la Educación Virtual: aprender y enseñar con las Tecnologías de la Información y la Comunicación. Madrid: Morata.

COLLAZOS, C. A., GUERRERO, L., y VERGARA, A. (2001): "Aprendizaje colaborativo: un cambio en el rol del profesor". Memorias del III Congreso de Educación Superior en Computación, Jornadas Chilenas de la Computación, Punta Arenas, Chile. Disponible en: http://www.dcc.uchile.cl/ luguerre/papers /CESC-01.pdf [Consulta: 8 de septiembre 2011]

DE HARO, J.J. (2009): "Usar Twitter en los centros educativos". Educativa. Blog sobre calidad e innovación en la educación secundaria. Disponiblle en http://jjdeharo.blogspot.com/2009/08/usar-twitter-en-los-centroseducativos.html [Consulta: 11 de septiembre 2011]

DE LA TORRE, A. (2006): "Web Educativa 2.0.". Revista electrónica de tecnología educativa, $\mathrm{n}^{\circ}, 20$. Disponible en: http://edutec. rediris.es/Revelec2/revelec20/anibal20.pdf [Consulta: 12 de agosto 2011]

DÍAZ, J. (2009): "Herramientas 2.0: Twitter en educación”.Educ@conTIC.El uso de las TIC en las aulas. Disponible en http://www.educacontic.es/ blog/herramientas-2-0-twitter-en-educacion [Consulta: 9 de septiembre de 2011]

Dirección de Investigación y Desarrollo Educativo. Vicerrectoría Académica, Instituto Tecnológico y de Estudios Superiores de Monterrey: Aprendizaje colaborativo. 
http://www.itesm.mx/va/dide2/tecnicas_didacticas/ac/Colaborativo.pdf [Consulta: 21 agosto del 2011]

GARCÍA ARETIO, L. (2007): “¿Web 2.0 vs Web 1.0?” BENED, 1-8. Disponible en: http://www.raco.cat/index.php/dim/article/viewFile/76637/98327 [Consulta: 17 de julio 2011]

GARCÍA GRANJA, M. ' J. (2010): "Redes sociales aplicadas a la educación". Revista Digital CSI-F Andalucía, $\mathrm{n}^{\circ}$ 28, 1-13. Disponible en: http://www.csicsif.es/andalucia/modules/mod_ense/revista/pdf/Numero_28/MARIA\%20JESUS_\% 20GARCIA\%20GRANJA_1.pdf [Consulta: 20 de julio 2011]

GARRIGÓS, I., MAZÓN, J. N., SAQUETE, E., PUCHOL, M., y MOREDA, P. (2010): "La influencia de las redes sociales en el aprendizaje colaborativo". Actas de las Jornadas de la Asociación de Enseñantes Universitarios de Informática. Julio 2010, Santiago de Compostela. Disponible en: http://www. aenui.net/ActasJENUI/2010/Jenui2010 67.pdf [Consulta: 14 de junio 2011]

LANDETE, S. (2009): "Diez formas de usar Twitter en el aula". Tecnotic. Tu portal TIC de tecnologías. Disponible en http://www.tecnotic.com/content/10formas-de-usar-twitter-en-el-aula [Consulta: 9 de septiembre de 2011]

Ley Orgánica de Educación, 2/2006 de 3 de mayo. Disponible en http://www.boe.es/boe/dias/2006/05/04/pdfs/A17158-17207.pdf [Consulta: 1 de septiembre 2011]

LLORENS CERDÁ, F., y CAPDEFERRO, N. (2011): “Facebook's Potential for Collaborative e-Learning". Revista de Universidad y Sociedad del Conocimiento (RUSC). Vol. 8, No 2, pp. 197-210. UOC. Disponible en $\mathrm{http} / / /$ rusc.uoc.edu/ojs/index.php/rusc/article/view/v8n2-llorenscapdeferro/v8n2-llorenscapdeferro-eng. [Consulta: 12 de octubre 2011].

LÓPEZ SÁNCHEZ, J. (2007): “Trabajo colaborativo". III Jornadas de Centros TIC. Aplicaciones Didácticas con las TIC Educación Primaria. Disponible en: http://www.omerique.net/twiki/pub/TIC/ActividadFormacion081106FC005/Tra bajoColaborativo_v1.pdf [Consulta: 21 de agosto 2011]

MARTÍN-LABORDA, R. (2005): "Las nuevas tecnologías en la educación". Cuadernos/Sociedad de la información, $\mathrm{n}^{\circ}$ 5. Fundación AUNA. Disponible en: http://www.telecentros.info/pdfs/05_06_05_tec_edu.pdf [Consulta: 3 de septiembre 2011]

NEGRE BENNASAR, F., y PEREZ GARCÍAS, A. (2010): "Del blog del aula al trabajo colaborativo con las TIC: modelo de colaboración entre universidad/escuela". XIII Congreso Internacional EDUTEC 2010: E-Learning 2.0: Enseñar y Aprender en la Sociedad del Conocimiento. Disponible en: http://gte.uib.es/pape/gte/sites/gte.uib.es.pape.gte/files/DEL\%20BLOG\%20DE \%20AULA\%20AL\%20TRABAJO\%20COLABORATIVO\%20CON\%20LAS \%20TIC.pdf [Consulta: 10 de septiembre 2011]

PALOMO LÓPEZ, R., RUIZ PALMERO, J., y SÁNCHEZ RODRÍGUEZ, J. (2008): Enseñanza con TIC en el siglo XXI. La escuela 2.0. Sevilla: Mad. 
Real Decreto 1513/2006, de 7 de diciembre, por el que se establecen las enseñanzas mínimas de la Educación primaria. Disponible en http://noticias.juridicas.com/base_datos/Admin/rd1513-2006.html [Consulta: 12 de agosto 2011]

Real Decreto 1720/2007, de 21 de Diciembre, en el que se aprueba el Reglamento de desarrollo de la Ley Orgánica 15/1999, de 13 de diciembre, de protección de datos de carácter personal. Disponible en http://noticias.juridicas.com/ base_datos/Admin/rd1720-2007.t2.html [Consulta: 12 de agosto 2011]

RICARDO BARRETO, C., y CHAVARRO, A. (2010): "El uso de Facebook y Twitter en educación". Lumen, $\mathrm{n}^{\mathrm{o}} 11,1-9$, Disponible en: http://www.accpol.org/divisiones/iese/lumen/ediciones/11/articulos/el-uso-defacebook-y-twitter-en-educacion.pdf [Consulta: 1 de agosto 2011]

SANCHO, J. M. (2008): "De TIC a TAC, el difícil tránsito de una vocal". Investigación en la escuela, 64, 19-30. Disponible en: http://www.ub.edu/esbrina/docs/projtic/tic_a_tac.pdf [Consulta: 7 de septiembre 2011]

TORO ARANEDA, G. (2010): "Usos de Twitter en Educación Superior". Serie Bibliotecología y Gestión de Información, $\mathrm{n}^{\circ}$ 53, 3-28. Disponible en: http://eprints.rclis.org/bitstream/10760/14190/1/Serie_N\%C2\%BA_53_Enero_2010_Uso_de_Twitter_en_la_Educaci\%C3\%B3n_Superior.pdf [Consulta: 1 de septiembre 2011$]$ 